\title{
DO EXAME CLINICO GERAL EM UROLOGIA
}

(SETIMO PONTO DA PARTE GERAL DO PROGRAMA DA CADEIRA DE CLINICA UROLOGICA DA FACULDADE DE MEDICINA DA UNIVERSIDADE DE S. PAULO) Serviço do Professor Luciano Gualberto

\section{CARLOS DE MORAES BARROS}

(2.0 assistente)

O conceito da unidade organica em medicina implica, mesmo dentro das especialidades como a Clinica Urologica, preliminarmente um estudỏ clinico geral. Nem doutra forma se poderia conhecer o individuo são ou doente se o organismo é um todo indivisivel impossivel de parcelar para estudar separadamente um sistema ou orgão sem considerar suas correlações com o todo num perfeito conhecimento dó cońjunto anatomico e funcional. O maravilhoso trabalho de CARreL "O homem, o desconhecido" vem culminar o periodo unitarista da medicina após a larga especialisação em que esteve por muitos anos, isolados os especialistas, como que em compartimentos estanques dentro dos sistemas e aparelhos integrantes das suas secções. Hoje o especialista é antes de tudo um clinico geral. E' de fazer-se justiça, entretanto, a especialisação que redundou num maior conhecimento do detalhe a beneficio do todo que ora de novo se corporifica.

Passada que foi, tambem, a era pasteuriana em qué mais se fasia medicina estudando o microbio do que o organismo humano aparece novamente no terreno da ciencia medica a concepção hipocratica unicista e de novo se consideram as predominancias deste ou daquele temperamento individual como capaz de reagir diferentemente em face das doenças. Não existem doenças mas doentes, organismos que diversamente se comportam perante as agressões a que se espoem. Daí o valor dado em nossos dias aó estudo da biotipologia que as éscolas alemã, francesa e italiana reuniram em doutrina com PeNDE modernamente a frente como maior autoridade pelos seus trabalhos e estudos.

Tendo $\mathrm{em}$ vista essas noções capitais é que se inscreve em nosso programa "Do exame clinico geral em Urologia". Exame clinico cuidadoso, acurado, compreendendo desde a anamnése a mais perfeita (qualificativos, historico dos antepassados e historico do doente até o momento da queixa atual) ás minucias do exame propedeutico geral. 
A formação do especialista subordina-se em qualquer terreno a formação do clinico e do cirurgião. A propedeutica dita urologica cujo estudo se fảrá meticulosamente na sequencia do curso, em aulas praticas, só o é nos detalhes e na riquesa de instrumental e material que a arte de esplorar o doente fornece ao observador. Cabè ao medico evitar quanto possivel os erros de observação, de esperimentaçâo e de interpretação que falseam os dados de diagnostico, prognostić e tratamento. E' só o contanto diario com o doente que dá e aprimóra a esperiencia clinica pessoal e proporcionará amanhã o que se chama "intuição medica" unica capaz de minorar erros com o conhecimento dos sinaes ou sintomas, sua importancia e significação. Erros, se são frequentes é justamente por que na sua maioria promanam da caracteristica dos elementos intuitivos porquanto grande parte dos dados semiologicos que se reunem tanto com a inspeção, percussão, palpação còmo ausculta sujeitam-se quasi que unicamente a juizo intuitivo.

Nesta mesma ordem de ideias e ainda mais e principalmente no Brasil onde poucos são os grandes centros e o sertão, de minguados recursos, predomina, devem os medicos concluir os seus cursos dentro de espirito eminentemente clinico. MaCKenZIE, ha.20 anos passados, já escrevia na Inglaterra combatendo a sujeição da clinica aos exames complementares. Aquele mestre da propedeutica universal batia-se desde então pela rehabilitação do exame clinico que deve orientar e encaminhar o diagnostico a ser secundariamente confirmado ou infirmado pelos exames ditos complementares como os de laboratorio, radiologicos e outros. O nosso Brasil precisa de medicos clinicos antes de tudo, capazes de interpretar sintomas e avaliar da marcha variada e caprichosa das doenças mesmo independentemente dos preciosos recursos complementares para, em qualquer recanto longinquo deste vasto e maravilhoso paiz, poderem acertar algumas vezes no prognostico, fazendo obra util aos doentes orientando-os para o tratamento mais eficiente.

O exame clinico geral deve obedecer a normas estabelecidas para que a rotina faça o habito e os dados colhidos na anamnése e no exame fisico venham progressivamente esclarecer o observador e encaminhar o seu espirito para um diagnostico presuntivo. Não estamos mais na epoca das lesões anatomo-patologicas irremediaveis mas, preponderantemente em urologia, os recursos cientificos vêm criando uma era em que o diagnostico será possivel muito mais precocemente, isto é, antes mesmo de se assestarem as alterações organicas, numa fase em que só a função está perturbada. Nesse objetivo é que devem todos os trabalhadores da medicina se orientar porque só diagnosticando cedo póde $\dot{0}$ medico fazer obra util ao doente. Outro não é o objetivo geral da medicina que terá culminado o seu ideal em todos os seculos quando chegar a higiene. Para tanto deve o medico pesquisar os sinaes subjetivos referidos pelo doente e não esperar que o diagnostico the fira os olhos com lesões organicas já então dificeis ou impossiveis de remediar. E' o momento de faser medicina fisiologica. Em urologia tão 
esmerados são os meios e processos de investigação propedeutica que podemos dizer estar este ramo da medicina na sua fase fisiologica.

LICHTENBERG criando a patologia de sistema e a seguir a urografia de eliminação deu a esta especialidade o impulso que a fez culminar nesse desideratum.

Para perfeita interpretação de sintomas quer objetivos quer subjetivos é inđispensavel o conhecimento dos reflexos e da complexidade dos seus arcos desde o mais simples (hipersensibilidade cutanea) aos mais complicados e associados (vicero-motores). Sem nos demorarmos no seu estudo que o curso desta Faculdade tão bem proporciona nas suas cadeiras, salientamos a necessidade do completo conhecimento deles como indispensavel ao clinico para, num interrogatorio de doente, retirar o maximo de informações uteis ao diagnostico. E, mais, ainda, importa o conhecimento da patogenia para poder alcançar com segurança a causa morbida. Um exemplo corrente em clinica urologica: individuo idoso com perturbações gastro-intestinaes tipo "dispepsia urinaria": perda de apetite, sêde pronunciada, digestão dificil, lingua saburrosa, ventre distendido e não raro nevralgias, caimbras e cefaléa, póde parecer, pela sintomatologia, um doente do transito intestinal quando a causa reside toda na obstrução urinaria que o adenoma ou o tumor da prostata acarretam. E' a intoxicação urinaria que repercute, nesta fase ultima, em toda a economia e leva o doente a consulta impressionado com os disturbios digestivos e esquecido dos padecimentos urinarios que anteriormente o molestaram e o interrogatorió inteligente rememora e acentua. No estabelecer a patogenia que resalta a correlaçẵo organica tanto da anatomia como dá fisiologia patologicas o clinico está realisando obra de encadeamento, de integração, de unidade. Esta do exemplo citado se refere a repercussão de lesão do trato urinario na economia geral, principàlmente no aparelho gastro intestinal. $O$ inverso tambem frequentemente se verifica nas infecções focaes. Inutil será tratar-se uma pielonefrite tentando esterilisar completamente o sistema urinario se vamos deixar fóco de infecção, que a ocasionou, quer nas amidalas, quer nos dentes, quer no sistema osseo ou no gastro intestinal: a infecção permanecerá ou, se desaparecer, reaparecerá. Outros e outros exemplos nessa mesma ordem de ideias delongariam por demais esta aula. Não deixaremos de lembrar entretanto, que ao urologista muitas vezes cabe diagnosticar precocemente um caso de tabes ao fazer cistoscopia e deparar com os sinaes caracteristos da afecção nas paredes da bexiga. E é esse um exemplo da correlação neuro-urologica. Quanto a correlações com a endocrinologia dia a dia se acentuam a medida que melhor se estudam as glandulas endocrinas e muito se vem publicando a esse respeito quanto a hipertrofia da prostata, o criptorquidismo e a impotencia que suscitam a interferencia dos mais complexos e completos conhecimentos medicos.

Antes de entrarmos propriamente na parte propedeutica é de referirmos que a clinica urologica comporta o estudo do sistema uroge- 
nital masculino e urinario feminino. O aparelho genital feminino é estudado na cadeira de Ginecologia.

Quando vamos fazer exame clinico geral e a' seguir detalhar propedeutica urologica devemos ter em mente as quatro caracteristicas clinicas desta ultima, tão bem sintetisadas por HINMAN :

1) A unidade do trato uro-genital.

2) A distinção entre lesões obstrutivas e não obstrutivas.

3) Distinção entre lesões infectadas e não infectadas.

4) Distinção entre metodos de exame não instrumentaes e instrumentaes.

A unidade do trato certo é corolario da unidade organica e dentro, portanto, da mesma concepção. Para facilidade do estudo, entretanto, divide-se o trato urogenital em urinario ou superior, compreendendo (rim, calices, bacinete e ureter) e inferior ou genital, do meato até o colo vesical incluidas as glandulas testiculares, bolsas, epididimos etc. bem como vesiculas seminaes, prostata e glandulas uretraes. A bexiga formará a porção media do trato onde quasi sempre as lesões são secundarias oriundas quer de processos localisados no trato superior quer de localisação inferior. Esta noção de unidade importa, em qualquer lesão tanto superior como inferior, num exame completo de todó o sistema, por isso que tanto as lesões primordialmente do trato urinario como as do genital se propagam para o outro como para a bexiga. Tuberculose renal primaria póde apresentar lesão secundaria na bexiga, na uretra, na prostata, vesicula ou epididimos etc. Como tuberculose do epididimo se propagará para o trato medio e o superior e, mesmo, fechando em circulo, para o outro lado. Isso constitue a base do tratamento quer por nefrectomia, quer por epididimectomia num e noutro caso para evitar a repercussão no sistema. Um seminoma do testiculo propaga-se imediatamente, sem atingir cadeia ganglionar da virilha, para os ganglios iliacos e lombares obstruindo ureter e inutilisando o rim do mesmo lado. Tuberculose do epididimo ou da vesicula que se propaga para o rim homologo é lesão frequentemente observada. Malformações envolvendo uma parte do trato indicam necessidade de pesquisa de outras no trato todo. Essa a significação do caracteristico urologico quanto a "unidade do trato" revelando que qualquer localisação de lesão nesta ou naquela porção demanda exame de todo o sistema. A segunda caracteristica: "obstrutiva e não obstrutiva" condiciona dois grupos perfeitamente distintos. $E$ ' bastante ponderar sobre a função de eliminação que exerce o trato urinario para se julgar da perturbação que a obstrução acarretará. Se na bexiga, no colo vesical ou na uretra, repercutirá bilateralmente e se no ureter ou no bacinete, o fará no rim daquele lado. Obstrução ao escoamento da urina e estase consequente se não reconhecidas e deixadas evoluir 
o resultado final será a inutilisação do parenquima de um ou de ambos os rins com graves consequencias para o individuo desde que os orgãos lesados são vitaes para a economia. As lesões não obstrutivas estão isentas deste problema primario no tratamento. Quanto ao terceiro caracteristico, lesões infecciosas ou não, tanto podem sobrevir as obstrutivas como podem ser primarias e mesmo produzirem obstrução secundaria pela evolução do processo. E o tratamento da infecção se imporá ao lado da correcção e tratamento da obstrução ou não, se esta coexistir ou não. Se a infecção é secundaria a obstrução é frequente se obter esterilidade do trato tão logo se o tenha desobstruido. $O$ perigo da infecção urinaria nunca será demasiadamente ponderado e o restabelecimento de bôa drenagem é primacial e urgente para um tratamento eficaz. A quarta caracteristica urologica é a que estabelece distinção entre metodos de exame: não instrumental e instrumental. A historia de cada caso clinico ao lado do exame fisico não instrumental fornecem dados presuntivos dé diagnostico que orientarão e indicarão os exames instrümentaes necessarios para completar e firmar o diagnostico. Nenhuma especialidade possue o rico instrumental que o urologista tem a sua disposição. E'necessario fazer uso adequado do mesmo para poder atingir a segurança e firmesa que conseguem dar como em nenhum outro ramo da medicina.

Nesta aula "Do exame clinico geral em urologia" vamos tratar tão somente dos metodos não instrumentaes excluindo não só o exame radiologico que demanda aula especial pela sua importancia e estensão bem como o toque retal (prostata, vesiculas seminaes, ureter e deferente) e o vaginal que será materia de aula pratica, a parte, afim de possibilitar a todos o exame de varias lesões perfeitamente diferenciaveis por esse importante metodo propedeutico. No serviço de clinica Urologica da Faculdade existe folha de observação pela qual orientaremos comentarios oportunos. A identificação do doente reune dados que á primeira vista pareceriam sem importancia mas que a clinica nos demonstra terem real valor. A edade, por exemplo, nos casos de dificuldade a emissão de urina nos fará pensaŕ em estreitamentos uretraés nos individuos moços e em adenoma da prostata, tumores e diverticulos nos velhos. A naturesa do trabalho póde sugerir, ainda mais agora que o nosso Paiz se industrialisa, reações do sistema, em virtude da ação de agentes quimicos e fisicos sob os quaes exerça o paciente a sua profissão. A procedencia do individuo, desta ou daquela zona onđe parasitos ou infecções mais frequentemente - existam, poderá lembrar lesões dificeis de supor onde de habito não se as encontram. A seguir, entranilo na anamnése propriamente, assinalamos de inicio a queixa que traz o doente a consulta e a duração da mesma anotando imediatamente o historico da molestia atual com o relato do doente, incluidos todos os sinais subjetivos com a terminologia por ele empregada.

Esta é a parte subjetiva do exame. Representa a versão que o doente dá ao seu caso e que póde ter grande importancia principal- 
mente no que se refere a lesões iniciais, funcionaes, acarretando disturbios mais subjetivos que objetivos e palpaveis e justamente aquelas de terapeutica mais eficaz no que concerne a "restitutio".

Os antecedentes familiares constituem o topico seguinte da anamnese e não será necessario resaltar a importancia dos mesmos que todos têm presente a frequencia da tuberculose, do cancer e mesmo da litiase em certas familias. Antecedentes pessoais a começar pela inf̧ancia e com especial atenção para doenças infecciosas, como a escarlatina, capazes de deixar sequela de nefrite, bem como amidalites, tifo, historia dentaria, pneumonias, reumatismo, etc. Historia conjugal e menstrual, se fôr mulher, constatando epocas, regularidade destas, corrimentos entre as mesmas, metrorragias etc. Em seguida nos reportamos a molestias e traumatismos anteriores - seu carater, detalhar para estabelecer, si houver, possiveis correlações com a doença atual. Referir tambem a historia venerea do doente. Uretrites anteriores, complicações, „tratamentos, sequelas. Lesões ulcerativas dos genitaes externos, duração, tratamentos; assinalando acidentes secundarios ou terciarios se os houve. Operações (onde e quaes). Passa-se depois a inquirir sobre os habitos e não vamos deixar de lembrar a necessidade de interrogar com inteligencia para evitar que o doente impressionavel ou não, timido ou envergonhado, deixe de responder com verdade falseando dados uteis ás conclusões. Não tivemos o praser de ouvir do proprio mas, no Rio de Janeiro, na Faculdade de Medicina, ficou tradicional a pergunta de FrAncisco DE CAStro sobre alcool: "Tem cabeça forte para o alcool?" e áqueles que disso se lisonjeam apressam-se em afirmar que sim, enumerando até proesas de resistencia. Variada a frase de acordo com a categoria intelectual e psiquica do paciente e moldadas no mesmo tom as demais, muito se consegue do interrogatorio neste particular de habitos. principalmente quando se indaga sobre vida sexual e se deseja esclarecer acerca de masturbação na puberdade e excessos na mocidade que, só geitosamente conduzidos, os pacientes deste ou daquele temperamento, respondem com verdade. Á pergunta "bebe muito?", em tom mais ou menos de repreensão, até ebrios inveterados respondem pela negativa, uns temendo que se não lhes de maior atenção aos padecimentos atuais e apenas venha o conselho de "deixar a bebida" outros por não quererem desrespeitar o "doutor". Interrogatorio para ser bem conduzido e proficuo demanda conhecimento e inteligencia. Todos os habitos incluindo fumo, alcool, café, chá, toxicos, devem ser anotados.

Isto posto é o exame fisico que se inicia inscrevendo na ficha de observação o tipo constitucional do individuo. Na Clinica Urologica adotamos a classificação constitucional de Pende para consignarmos na folha de observação o biotipo individual. Entretanto nos limitamos a avaliação dos caracteristicos apenas morfologicos e mesmo destes fazemos constar correntemente o tipo de desvio se longitudinal se transverso, se misto ou quasi normolineo (longilineo, brevilineo, 
misto e quasi normolineo) e estabelecemos si a construção é forte. fraca ou normal (hiperstenico, hipostenico, normostenico). Poucas vezes nos referimos a massa corporea (hipersomico, hiposomico e mediosomico) porquanto preferimos anotar o peso habitual, peso atual e perda de peso e de forças para melhor acentuarmos a marcha de doenças debilitantes ou caquetisantes como tuberculose, cancer etc. O carater racial vem inscrito no inicio da ficha de observação, na qualificação ou identificação do doente. Os demais caracteristicos do quadro de Pende como temperamento funcional, carater moral e tipo de pensamento, são por demais complexos e não têm ainda correlação perfeitamente estabelecida com a pratica diaria urologica em face dessa mesma complexidade. LlchTENBERG tira conclusões praticas da assinalação do biotipo se longi, se brevi ou normolineo quanto a palpação renal. Os longilineos, segundo aquele professor, têm rins palpaveis, sendo que o direito muita vez o é nos seus $2 / 3$ inferiores e o esquerdo apenas no polo inferior e em individuos de rins perfeitamente normaes o que não era admitido pela escola francesa que considerava patologico todo rim palpavel. Os quasi normolineos têm o polo inferior do rim direito palpavel na normalidade e o rim esquerdo já não o é enquanto que nos brevilineos, normalmente, são impalpaveis os rins e quando se os palpa ou são moveis e ptosados ou aumentados de volume. Anotamos na ficha, tambem, a altura do doente e as oscilações de peso conforme já nos referimos, passando, em seguida, ao exame geral onde assinalamos aspeto geral do doente, facies, desenvolvimento muscular e quaesquer sinaes que ó individualisem taes como cicatrizes, manchas, placas, etc., da epiderme. Nesta parte do exame verificamos pulso, seus caracteristicos, pressão arterial e temperatura. Passa-se então ao exame especial dos diversos aparelhos. Ha sempre, anteriormente, no que se refere a cada aparelho, um exame subjetivo e o questionario deve ser de tal forma orientado que não conduza o doente a respostas neste ou naquele sentido. $O$ clinico esperimentado, em face do doente timido mas desejoso de obter o maximo de atenção do medico, sabe como muitas vezes a resposta a pergunta "sente isto ou aquilo", é sempre afirmativa para que o exame seja mais cuidadoso... O exame naturalmente começará pela cabeça, orgãos dos sentidos e sistema nervoso, reflexos etc. A seguir examina-se o pescoço e depois coração e aparelho circulatorio bem como o respiratorio é o gastro intestinal terminandose com exame das extremidades do individuo.

Não são poucos os prostaticos que procuram o medico por dores sacras que nada mais são do que reflexos de processos naquela glandula incluindo cancer com metastases. quer no iliaco quer nos ossos da perna e que o exame radiologico vem confirmar. A boca deve ser cuidadosamente examinada, amidalas e dentes e estes devem ser radiografados quando já desvitalisados principalmente nos casos de infecções urinarias que podem ser secundarias a procèssos localisados nas raizes dos mesmos taes como kistos, granulomas e inflamações. 
Terminada esta parte do relatorio passa-se ao aparelho uro-genital. Dentro do exame físico urologico, como já dissemos, sómente inspeção, percussão e palpação é que vão fazer parte desta primeira. aula.

Inspeção - Claro está que quando vamos cuidar da inspeção particularisada do aparelho genito urinario já fisemos a inspeção geral, avaliação do individuo como ser humano, espressão facial, postura, deformidade, movimentos respiratorios, gestos e superficie da epiderme, como ficou dito e nesta parte tão sómente nos preocuparemos com inspeção local. Começaremos pelos orgãos genitaes externos tanto no homem como na mulher afim de observarmos qualquer desvio visivel do normal. No homem, o exame do penis deve ser um exame perfeito do orgão, tamanho, anomalias de numero, desenvolvimento, torsões, aspeto, presença de cicatrises, ulcerações etc. na glande ou no sulco balano-prepucial, constatação de varices etc. Exame do prepucio, facil, dificil ou mesmo impossivel esteriorisação da glande caracterisando as fimoses, presença de parafimose, fistulas (trajéto e localisação das mesmas) edemas, dermatoses, elefantiases, tumores etc. Exame detido do meato uretral, posição do mesmo se central e normal ou deslocado mais ou menos para a face superior ou dorso do penis (epispadia) ou mais ou menos para a face inferior (hipospadia), angustiamentos e bridas. Verificar-se-ha presença de secreções (corrimentos) e nesses casos, aspeto do meato, côr, se edemaciado e hiperemiado nas bordas indicando processos agudos ou, em caso contrario, cronicos. Inspeção das bolsas e seu conteudo. Presença ou ausencia de edemas, dermatoses, inflamações, fistulas, ulcerações, elefantiase, tumores. A simples inspeção as vezes revela a ausencia de testiculos nas bolsas que a palpação vae confirmar e muita vez tambem só pela inspeção se constata presença de grossas veias turgidas indicando as varicoceles. A percussão nada revela nessa porção do trato e passa-se imediatamente a palpação das bolsas que é rica de informações. A palpação nos revelará presença de hernias escrotaes, de derrames na vaginal (hidro ou hematocele, fasendo-se transiluminação para diagnostico diferencial). Examina-se os testiculos fasendo com que escorreguem delicadămente entre os dedos para a frente e para traz e ter-se-ha caracteristicos de tamanho, tensão dos mesmos, presença do sulco entre eles e os epididimos e estados patologicos dos mesmos. Cérto a palpação nos informará sobre a presença dos testiculos nas bolsas respetivas, o seu numero e si em posição e situação normaes (torsões). Na ausencia de um ou de ambos verificar si se trata de criptorquidia (parada uni ou bilateral do testiculo durante a sua migração da sua posição fetal inicial para a bolsa. Essa parada póde se verificar em qualquer porção do trajéto e as criptorquidias serão: abdominaes, inguinaes ou escrotaes altas) ou de ectopias (testiculos fóra das bolsas e fóra do trajéto normal de sua descida migratoria. admite-se que, 'nestes casos, o gubernaculum testis é o responsavel pelo desvio puxando o testiculo para: logo acima do pubis ou sobre 
o triangulo de Scarpa oú para a região perineal e aí os tres tipos de ectopias: pubiana, femural e perineal). Fóra ou dentro das bolsas devem os testiculos ser examinados, pela sua sensibilidadé, consistencia etc. para verificar inflamações agudas e cronicas, tumores etc. e se fazer o necessario diagnostico diferencial entre orquites propriamente ditas e epididimites. Estas ultimas são muito frequentes. na blenorragia e o inicio das mesmas é na cauda do epididimo (via canalicular de infecção). emquanto que as orquites são mais comumente encontradas após inf£cções sistєmicas taes como parotidites, gripes, tifo etc. ou, ainda, na tuberculose e na sifilis. A maior parte dos diagnosticos de orquite outra cousa não são que processos epididimarios erroneamente ditos testiculares. Aliás, é necessario palpar-se com atenção grande numero de testiculos e epididimos normaes para que se familiarise e se reconheçam variações ligeiras de consistencia e de aderencia dos mesmos no sulco normal que os separa (fig. 1). Ha dias, no Ambulatorio de Urologia, nos apareceu individuo moço com historia de polakiuria tipica de tuberculose e que

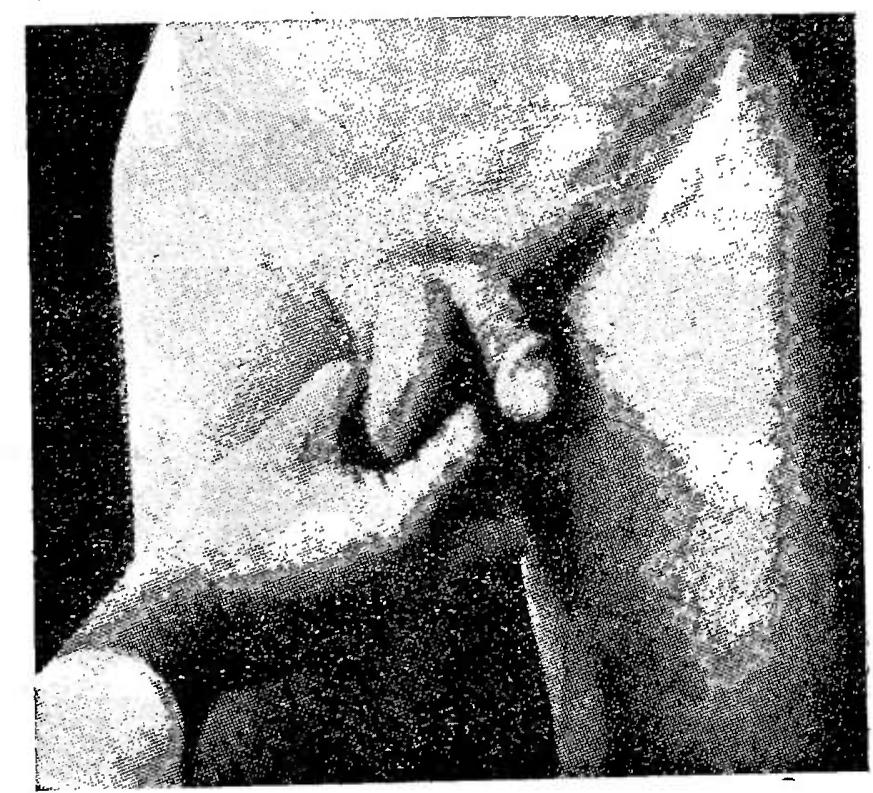

FIĞ. 1

(Bailey)

os exames complementares confirmaram inteiramente. Esse moçor 32 anos de edade, casara-se ha sete anos e sua esposa teve um unico filho que conta hoje 6 anos e meses. Trez meses após o matrimonio percebeu a primeira dôr a micção e desde essa época the apareceu necessidade frequente de urinar (polakiuria) que se acentuou e permanece tendo dôr ao iniciar e terminar as micções que se contam em numero de 30 e mais vezes durante o dia e numerosas durante a noite. Testiculos e epididimos tinham sido dados na observação como bilateralmente normaes quando, na revisão a que submetemos no serviço todas as observações dos grupos, tratando-se de caboclo 
do nosso interior que desconhece os passes da "arte de evitar filhos", chamou-nos a atenção o inicio da molestia 3 meses após o casamento e o filho unico do casal com a edade de 6 anos e meses. Um exame cuidadoso dos orgãos genitaes nos fez constatar testiculos e epididimos "grosso modo" normaes, porém, a palpação mais detida revelou ausencia de sulco de limitação, e aderencia entre testiculo e epididimo de cada lado e estes como que empastados e com pequenos nodulos. Foi a tuberculose que, tomando os genitaes e obstruindo canaes esterilisou o doente. E a historia patogenica dessa forma se. desvenda.

O exame nos póde evidenciar tlimores e kistos do epididimo e proseguindo palparemos o canal deferente desde a cauda do epididimo até a sua terminação no canal inguinal. Nessa altura estamos na mão com o cordão espermatico e os elementos remanescentes do processo funicular (ligamento de CLOQUET) o musculo cremaster e as membranas testiculares, as arterias espermatica e cremasterina, a arteria deferencial, o plexo venoso pampiniforme e o ramo genital do nervo genito crural alem de linfaticos e fibras do nervo simpatico que devem ser examinados. Lesões isoladas do deferente ou do cordão são muito raras, via de regra provêm de lesões de estruturas com as quaes se associam. Assim, a primeira porção do deferente, nas proximidades do epididimo, '”se afeta quando este é lesado emquanto a sua porção terminal, no anel interno do canal inguinal, é envolvida nas lesõ es da prostata e vesiculas. Processos agudos são mais frequentes que os cronicos e via de regra propagações de lesões iniciais da uretra posterior.

Poderemos cónstatar contusões, torsões do cordão, hidroceles, kistos, gomas, tumores bem como a presença de varices (varicocele) que, se de pouca significação a esquerda pela esplicação mecanica que dá o trajeto mais longo da veia espermatica desse lado e a sua confluencia em angulo reto com a veia renal já a direita poderia indicar neoplasias do rim homonimo. Não -vamos esmiuçar torsões não só dos testiculos, como da hidatide pediculada de MorgagnI, do corpo de Giraldes e bem assim de outros recessos anatomicos porquanto a sua raridade não as deve faser incluir num estudo propedeutico geral. Não deixaremos de assinalar, porém, os casos de orquite ou epididimite em testiculos ectopicos ou nas criptorquidias que podem, as vezes, dar a impressão de "abdomen agudo" ou mesmo podem produsir essa sindrome.

A palpação do penis póde demonstrar a presença de "induratio penis" que é uma transformação fibrosa, fibro-calcarea ou mesmo ossea, do énvolucro dos corpos cavernosos e de etiologia desconhecida. Sempre se situa na face dorsal e são placas mais ou menos estensas e mais ou menos rijas, as vezes de consistencia dura como a ossea. Palpa-se a uretra e não raro, mismo sem o auxilio de sonda, consegue-se distinguir nodulos de estreitamento e tumefações de litrites que aquele processo de exame e outros confirmarão. 
$\mathrm{Na}$ mulher o exame dos genitais externos se fará na parte correspondente ao exame dos diversos aparelhos mas ao urologista cabe verificar. o meato, sua situação, presença ou ausencia de secreção, presença de polipos ou mesmo veia varicosa capases de, acarretar obstrução. As veses a simples inspeção demonstra presença de prolapsos da bexiga, fistulas uretro ou vesico vaginaes. A parte de toque vaginal correspondente a palpação será dada na aula especial referente ao toque urologico.

A inspeção póde, ainda, revélar presença de infartamento das cadeias ganglionares, reação de defesa demonstrando existencia quer de processos agudos quer processos outros como na sifilis, linfogranulomatose ou doença de Nicolas Favre. E a palpação completará o exame verificando presença ou ausencia de flutuação etc.

Passa-se, a seguir, a inspeção da bexiga.

Nos individuos magros, tanto homens como mulheres, si a bexiga estiver muito distendida formará como que um globo no abdomen, lógo acima do pubis e na linha media. Em individuos mais gordos não se a consegue visualisar (fig. 2). Nas grandes retensões (as vezes atingem litros) o globo vesical visualisavel chega as proximi-

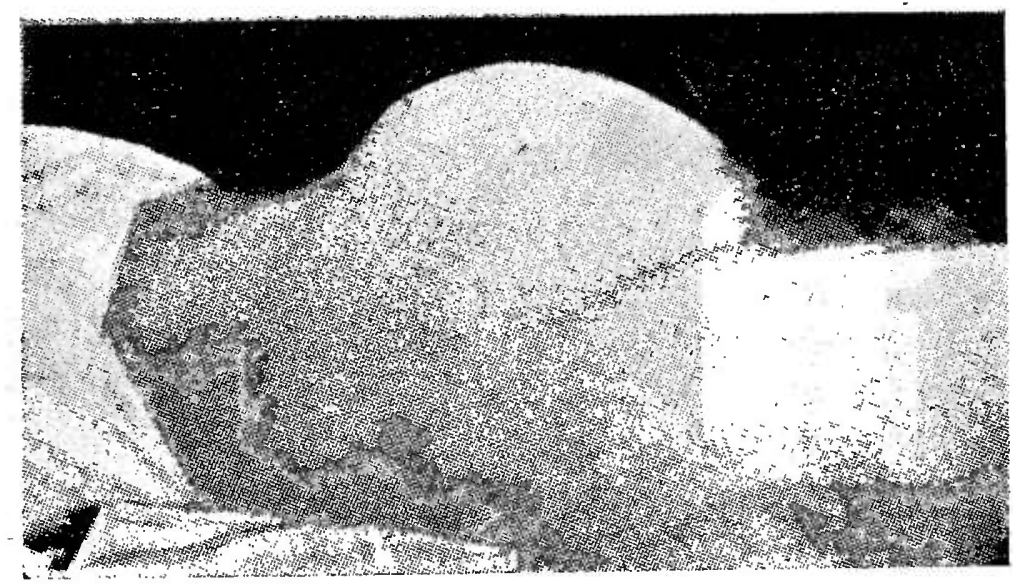

FIG. 2

(Bailey)

dades da cicatriz umbelical com maior eixo no sentido vertical. São retensões quer por estreitamento de uretra, tumores da prostata ou lesões de origem nervosa e obstruçóes por utero gravido. Noutros casos o tumor formado pela bexiga repleta e distendida se apresenta desviado para a esquerda ou para a direita principalmente quando existem diverticulos ou coleções de processos de pericistite. Mésmo nessas grandes retensões, entretanto, quando se trata de individuos muito gordos, o sinal póde falhar e a inspeção nada constata, a bexiga se distente pela bacia. Ausente o sinal, portanto, nesses casos, não significa inexistencia de retensão.

$\mathrm{Na}$ mulher, além disso, kistos do ovario pódem se desenvolver na linha mediana e ocasionar confusões ou vice-versa, daí a necessi- 
dade de iniciar o exame esvasiando a bexiga, naturalmente com os cuidados necessarios para evitar descompressão brusca e suas consequencias, como hemorragia "ex-vacuo".

- Dentre as nualformações a estrofia da bexiga é diagnosticavel a simples inspecção e a parede posterior, que vem se implantar lógo acima do pubis, se apresenta com trigono, musculo inter-uretral e meatos a ejaculalrem aos olhos do observador. Kistos ida uraca formam tumores suprajacentés a região vesical.

A percussão da bexiga nada revelará de preciso nem mesmo se está de fato distendida. Nos casos de retensão aguda, completa, o globo vesical elevado, no abdomen, dá massicez conípleta mas nas retensões cronicas a bexiga se distende sobretudo pela bacia e póde não ser percutivel, escondida pela sonoridade de alças intestinaes. A percussão deve ser feita com a mão espalmada e colocada tão profundamente quanto possivel afim de se aproximar o mais possivel da bexiga e se conseguir som vesical e não de alças intestinais. A mão deve estar aflorando a borda do pubis e percute-se sobre os dedos, sem' os deslocar. Havendo massicez assinala-se que atinge a um ou mais dedos transversos acima do pubis ou, milhor; reporta-se a. seguir, a centimetros.

Palpação vesical - permite examinar principalmente a sensibilidade da bexiga. Tanto se consegue avaliar essa sensibilidade fasendo pressão com a mão espalmada que deprime progressivamente a parede abdominal ao nivel da bexiga e levantando-a bruscamente o que provoca dôr acentuada nas cístites graves como a simples pressão já póde despertar reação dolorosa ao doente. Deve-se examinar as regióes iliacas onde fócos inflamatorios peri-vesicaes podem ser perceptiveis bem como ganglios linfaticos tumefeitos nos casos de tumores vesicaes. O toque combinado, retal no homem e vaginal na mulher, é preferivel e mais rico em informações mas constará da aula sobre toque em urologia que será materia a ser encarada a seguir.

Passamos agora a inspeção das regiões lombares, cuja delimitação clinica ou medico-cirurgica e urologica é diferente da delimitação estritamente anatomica. Em anatomia descrevemos uma região lombar que é aquela compreendida pela coluna vertebral e partes imediatamente visinhas. Em clinica, região lombar é a região ocupada pelo rim e seus anexos; consideramos, portanto, região lombar direita e região lombar esquerda e a sua delimitação é a seguinte: para fóra, uma linha vertical partindo da borda posterior da axila até o iliaco, para dentro a saliencia esterna da massa sacro lombar,- em baixo a linha sinuosa do iliaco e em cima uma linha transversa passando pela. apofise espinhosa da $11 .^{\mathrm{a}}$ vertebra dorsal. $\mathrm{O}$ aspeto esterior da. região é estremamente variavel com o sexo, o biotipo e a massa corporea, isto é, maior ou menor adiposidade o que influencia grandemente facilitando ou dificultando as explorações clinicas. Felismente é das regiões mais moveis do tronco o que facilita mánobras de exame e operatorias. Na mulher a musculatura sacro lombar é menos 
pronunciada e o talhe mais arqueado detalhes estes que desaparecem com grandes adiposidades. Claro está que sendo movel é região que sofre, no seu aspeto esterno, as modificações de posição. No exame da região lombar com o paciente sentado ou deitado sobre o ventre, quasi nada se consegue observar por isso que o plano que as ultimas costelas e os ligamentos costo-vertebraes formam não se sujeitam facilmente e só nos casos de flemões ou abcessos perinef riticos é que aparece abaulamento, havendo, as vezes, edema inflamatorio que é sinal valioso de processo inflamatorio do parenquima renal ou dos envolucros. Outras veses, entretanto, o abaulamento só aparece no ponto mais fraco: o triangulo de Petit.

Para o lado do abdomen é necessário que o aumento de volume do rim seja consideravel para que a simples inspeção o revele. A inspeção será feita tanto em decubido dorsal como em posição ortostatica examinando-se a região dos flancos entre falsas costelas e a crista iliaca e a região do hipocondrio correspondente, comparando-se, tamibem, com o outro lado. Hidronefroses ou pionefroses, sarcomas, rins policisticos quando volumosos pódem dar deformação apreciavel. São moveis com a respiração e deslisam sob a parede abdominál. As veses a compressão que o seu desenvolvimento exerce sobre, circulação venosa é de tal ordem que se desenham os vasos sob a pele e nestes casos constata-se verdadeira asimetria abdominal por abaulamento do flanco e até da fossa iliaca (sarcomas renais e rins policisticos). Quando o abaulamento de causa renal é bilateral o diagnostico de rim policistico quasi se impóe.

Percussão renal: A anatomia nos dá a rasão pela qual a percussão da região lombar é completamente negativa: o rim é quasi que inteiramente recoberto pela espessa massa muscular sacro lombar e a direita a sua massicez se confunde com a do figado e a esquerda com a do baço. Aliás GuYon já havia feito demonstração pratica percutindo um doente que sofrera nefrectomia um ano antes: não constatou diferença entre os dois lados.

Os classicos todos dão a percussão abdominal como capaz de fornecer dados interessantes mas nem sempre esclarecedores. Póde revelar tumor renal delimitando suas bordas interna e externa bem como polo inferior e constatando, o que seria de grande valor no diagnostico diferencial; presença de intestino sobreposto ao tumor (sonoridade formando faixa na zona de massicez). Este carateristico teria real válor e permitiria distinguir tumores do rim, dos do figado e baço. A situação diversa ocupada pelo colo ascendente a direita e o descendente a esquerda esplica a rasão pela qual a disposição. dessa faixa de sonoridade é diferente de um e de outro lado: a direita o colo ascendente é empurrado para dentro, sobre a borda interna do rim emquanto que a esquerda o colo descendente é impelido sobre a borda externa e deste lado a sonoridade é menos perceptivel não só por ser o colo levado para fóra mas tambem pelo estado de contração habitual do colo descendente. Nem sempre, entretanto, a faixa existe e encaminha diagnostico diferencial: de um 
e de outro lado, o rim, quando muito aumentado de volume, afasta os colos e vem faser saliencia no abdomen sem interposição de alças. e os demais exames propedeuticos é que virão fornecer dados para diagnostico positivo.

Ainda como percussão renal devemos referir a chamada "ma-nobra de GIORDANo" que é a percussão profunda da loja renal com a borda cubital da mão. $O$ doente sentado percute-se a loja renal em toda a sua altura com pancadas mais ou menos bruscas tanto a direita como a esquerda. Essa manobra provoca dôr acentuada no lado ou nos lados doentes. É manobra que apresenta seu valor. Sé a capsula renal ou o bacinete estiverem distendidos, sob tensão, o doente retira o corpo bruscamente em virtude da dôr que o choque produz. Quando se presume colica de causa renal o sinal é significativo mais ainda por que objetiva um fenomeno puramente subjetivo e confirma o relato do doente sendo que se apresenta positivonos calculos renaes e ureteraes durante a crise obstrutiva que produsem e é negativo nos intervalos.

A percussão, entretanto, como dissemos, não delimita o rim e desejar por meio dela apreciar modificações de volume e de forma é mais subtilesa semiologica que bôa pratica clinica por tudo que adiante se disse e ainda mais pelas condições instaveis de séde anatomica do orgão.

A palpação é o meio semiologico renal e ureteral por excelencia. Compreende, o exame para pesquisa de areas dolorosas, presença ou ausencia de defesas musculares, tumores, edemas bem como localisação de quaesquer variações de volume, de sensibilidade, delimitação de superficie e de bordas, consistencia, fixação etc. Para o exame de areas dolorosas devemos nos referir aos pontos ditos reno-ureteraes ou mesmo ureteraes. 'Exercendo-se pressão nesses pontos determina-se sensibilidade dolorosa que se reportava, segundo sua localisação, a alteração renal, pielica ou ureteral. Não se admite, geralmente, em nossos dias, que esses pontos tenham valor sintomatico segmentario e, antes, considerada a inconstancia da sua significação, apenas indicam alterações provaveis de um lado do sistema. Muita vez nem isso se póde afirmar considerado o arco complexo do reflexo reno-renal. Alem do mais é indispensavel que se tenha certesa de que o ponto constatado não é apendicular, intestinal ou genital em se tratando de mulher. São numerosos os pontos que se encontram citados nos tratados quasi tantos quantos os autores e com pequenas variações. Citaremos apenas aqueles que são pesquisados sistematicamente na clinica Urologica da Faculdade e omitiremos os demais. Uns são posteriores:

1 - o costo-vertebral (de Guyon) no angulo formado pela ultima costela e a coluna vertebral.

2 - o costo-lombar no angulo que a ultima costela forma com a borda da massa sacro-lombar. Este ponto deve ser preferente- 
mente pesquisado com o doente deitado afim de se anular a tensão. muscular.

Outros são anteriores:

3 - o sub-costal situado no ponto em que a borda esterna do musculo reto anterior do abdomen encontra a decima costela. No lado direito este ponto póde ser sensivel nas afecções da vesicula biliar.

4 - o ureteral superior (PASTEAU), tambem descrito por BAzY como para-umbelical, se encontra na intersecção de uma horisontal partindo da cicatriz umbelical e de uma vertical tirada do terço interno da arcàda crural.

5 - o ureteral medio (HALLÉ) que se encontra na intersecção: de uma linha horisontal unindo as duas espinhas iliacas anteriores e superiores e uma vertical tirada do terço interno da arcada crural. Nesse nivel o ureter crusa o estreito superior da bacia.

A palpação não consegue, normalmente, distinguir os ureteres a não ser em individuos muito emagrecidos e com processos muito acentuados de ureterite e periureterite. Será palpavel na porção em que crusa a linha móninada para penetrar na pequena bacia. Varios. pontos de referencia foram descritos para se precisar esta porção do. ureter. Alem disso, o ponto ureteral dito inferior póde ser tocado no homem pelo reto e na mulher pela vagina e terão a sua descrição na aula corresspondente a toque.

Como já referimos e de acordo com LichitenBERG o tipo constitucional do individuo modificando-lhe o talhe e a presença ou ausencia de adiposidade influenciam a palpação renal como a ureteral. Nos longilineos os polos inferiores dos rins podem ser palpaveis sem que isso signifique rins patologicos e o rim direito muita vez é palpavel em seus $2 / 3$ inferiores. 'Nos quasi normolineos o polo inferior do rim direito póde ser tambem palpado na normalidade do orgão e nos brevilineos os rins em estado higido não são palpaveis.

A anatomia esplica essa diversidade pois sabemos todos que o rim esquerdo está situado a cerca de 2 a 3 centimetros mais alto que o direito. Alem disso devemos lembrar que a situação desses orgãos. não é paralela a coluna mas inclinada para baixo e para fóra tanto que existe um afastamento de dois centimetros ou mais dos polos. inferiores com relação aos superiores, da linha mediana.

Muitos são os metodos descritos para a palpação dos rins, quasi todos bimanuaes e vamos nos referir principalmente áqueles mais correntemente empregados. Todos têm sua utilidade consideradas as condições individuaes como capazes de faserem variar os resultados. palpatorios de doente para doente. Variando necessariamente com o processo empregado as posições do medico e do doente estudaremos as mesmas na descrição particular que faremos.

Os rins normaes quando são palpaveis se apresentam com os caracteristicos da consistencia parenquimatosa, superificie lisa, limite 
inferior nitido e o superior só é sentido em condições anormais. A palpação não é dolorosa na normalidade.

\section{Palpação em posição dorsal:}

Processos de GuYon - Doente em decubito dorsal, braços distendidos ao longo do corpo, pernas em estensão (alguns preferem ligeira flexão obtida por pequeno coxim sob os joelhos) e todos os musculos em relaxamento, particularmente os da parede abdominal anterior. O medico deve colocar-se do lado do rim que vae palpar. O doente será aconselhado a respirar lenta mas profundamente. Si o rim a palpar é o direito, coloca-se os dedos da mão esquerda no angulo costo lombar fasendo-se pressạo de traz para diante afim de elevar o rim e apresenta-lo a mão direita, espalmada sobre a parede abdominal e para fóra dos musculos reto anteriores de tal forma que as pontas dos dedos se encontrem a dois dedos transversos sob o ponto de união da decima costela com as costelas superiores. A figura 3 mostra a posição. Para palpar o rim esquerdo a posição das

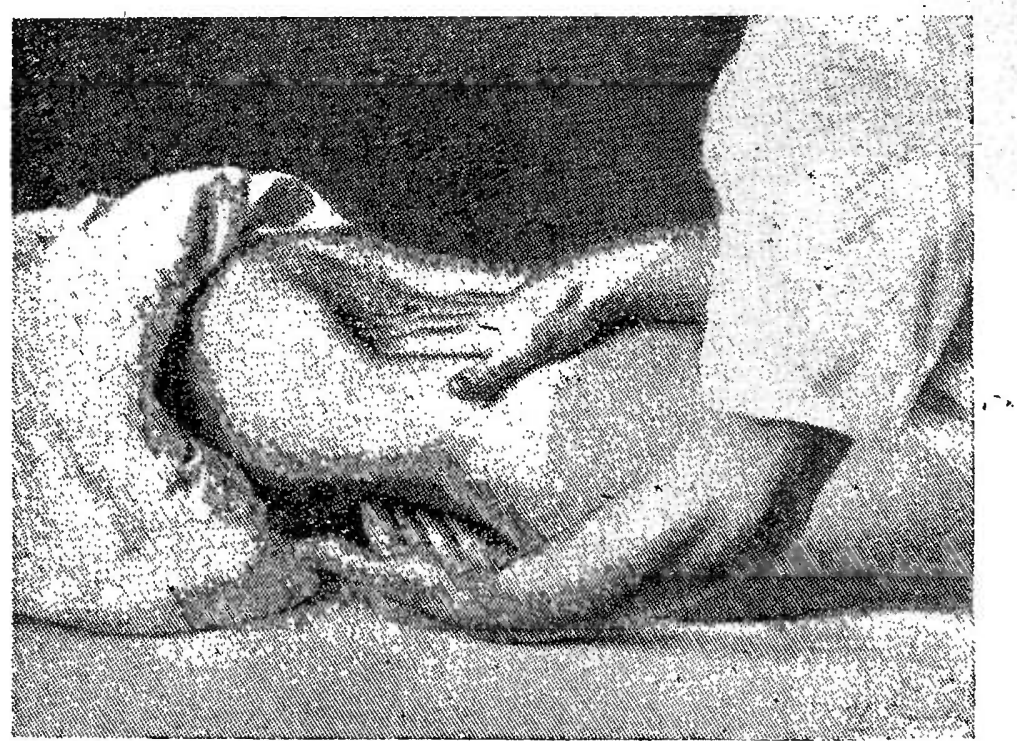

FIG. 3

Processo de Guyon (Legueu)

mãos é inversa: mão direita para baixọ e mão esquerda para cima. Nessa posição das mãos o doente deve ir respirando normalmente e aproveita-se toda inspiração para faser a mão abdominal penetrar mais profundamente, resistindo durante a espiração, afim de se manter deprimida a parede e quando o rim é palpavel, na sua descida inspiratoria, a mão abdominal o conseguirá sentir. Alguns chamam a este processo de metodo palpatorio de Trousseau.

Para o outro processo de GuYon, dito do rechaço renal (ballotement renal dos franceses) a posição é a mesma apenas com as falanges dos dedos da mão lombar ligeiramente flexionadas, no momento em 
que começa uma espiração o medico provoca pequenos movimentos bruscos que fazem com que o rim, situado posteriormente, venha chocar a mão abdominal que permanece deprimindo a parede. Sentese dessa forma, direção, volume, consistencia e caracteristicas de superficie. Nos casos de ptose, entretanto, se a mão abdominal deprime como deve a parede abdominal o rim não desce. Nos individuos magros póde-se aliviar de pouco esta pressão e sente-se o rim escorregar entre as mãos conseguindo-se fasê-lo voltar a loja por pressão entre as duas mãos, manobra essa que o doente muitas vezes percebe e refere. O rechaço renal não é devido a mobilidade do rim mas antes à um deslocamento em massa. Mesmo nos tumores aderentes está presente. Não é caracteristico de tumor renal e póde ser observado em tumores e malformações do figado, nas colecistites, tumores do colo mas nunca nos tumores do baço. O valor do sinal está em que um tumor que não o a'presenta via de regra não é renal. O processo de Glena:RD, entretanto, é preferivel nestes casos, como adiante veremos.

Processo de Petit — nada mais é do que uma variante do processo de Guyon e não apreseńtá vantagens. O medico fica do lado oposto ao que esplora, coloca a mão direita na parede abdominal para esplorar o rim esquerdo e a mão esquerda passa por baixo do paciente para vir se colocar na região lombar do outro lado (fig. 4). O inverso para o lado oposto.

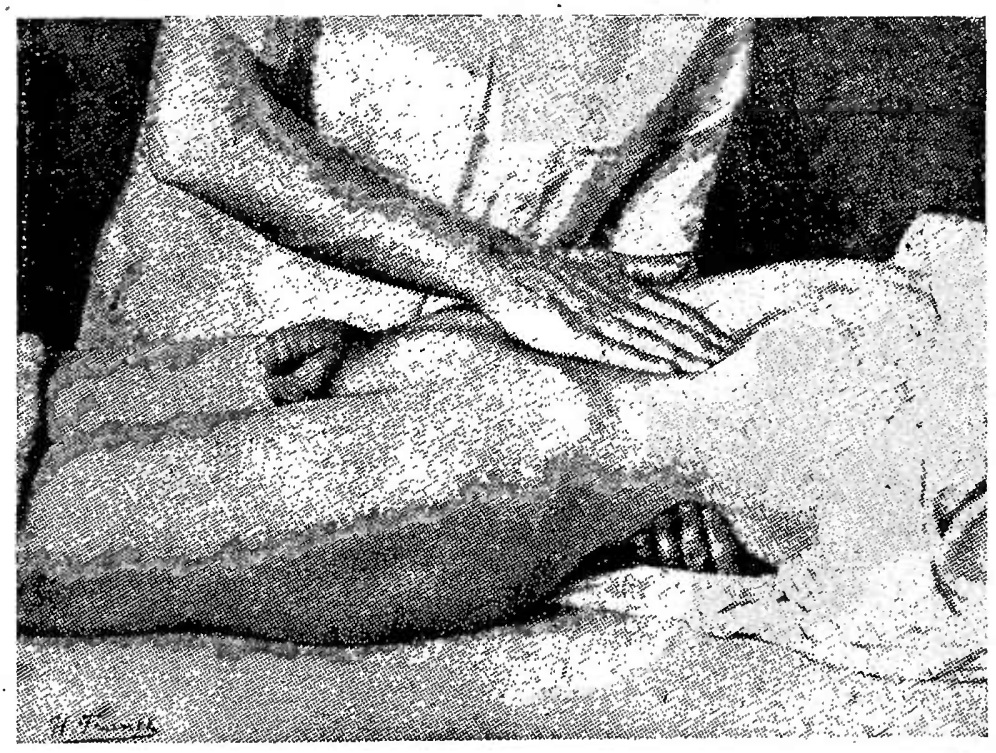

FIG. 4

Processo de Petit (Legueu)

Processo de Glenard - é o processo chamado da palpação nefroleptica, justamente porque melhor permite sentir os rins flutuantes out moveis, nos individuos magros. Paciente e medico nas mesmas posições descritas para os processos de Guyon. A mão de nome contrario ao lado examinado é colocada prendendo o flanco lógo abaixo 
das costelas, os quatro ultimos dedos dirigidos para o ángulo costo lombar e fazendo pressão de traz para diante emquanto que o polegar fica na frente ao nivel da parede abdominal, livre para os movimentos necessarios. A outra mão permanecerá espalmada sobre a parede anterior do abdomen na altura da reborda costal e na borda esterna do reto anterior. A sua função será deprimir a parede anterior do abdomen nas espirações e opor-se a mobilidade renal para dentro e tornar o rim mais acessivel aos dedos da região lombar (fig. 5).

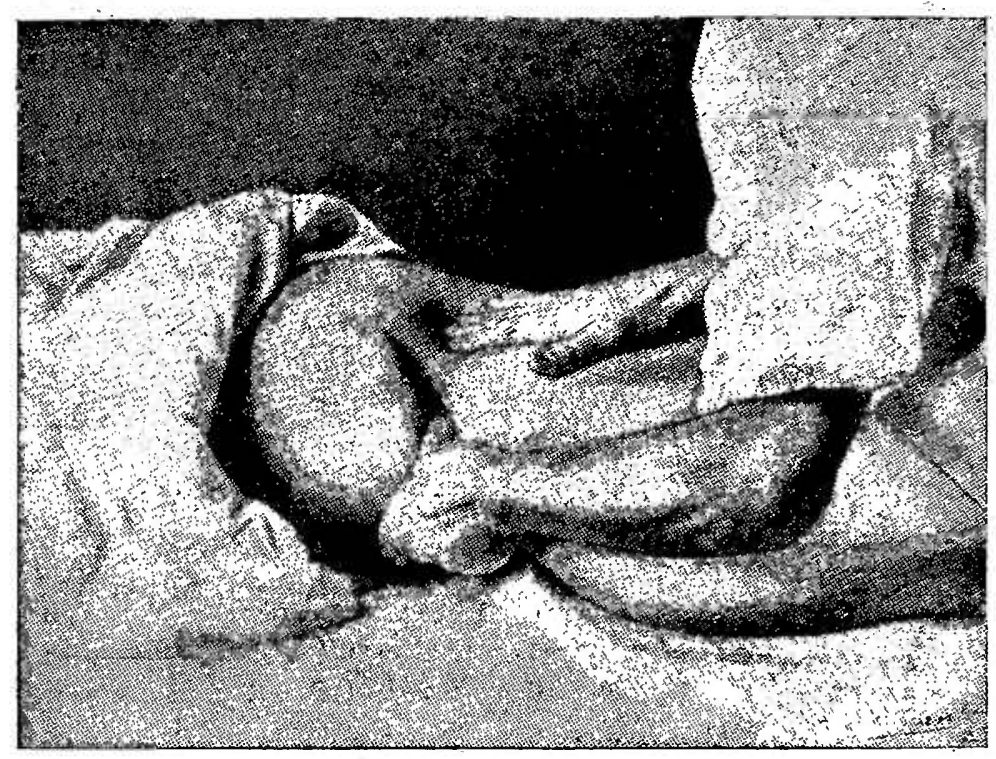

FIG. 5

Processo de Glenard (Legueu)

Dispostas dessa forma as mãos o doente executará movimentos respiratorios profundos sem que os dedos exerçam grande pressão. Em seguida, porém, logo após uma inspiração forte, que faz o rim descer, aproximam-se bruscaniente os dedos fazendo-se a manobra dita da capturação renal, e o rim fica preso entre o indicador e o polegar, si a mobilidade for grande. Bem mantido nessa posição, nesses casos, a mão abdominal póde vir palpar o rim preso e apreciar suas caracteristicas palpatorias. Quando a mobilidade é pequena ou média, ao se aproximarem os dedos na manobra de capturação, a pressão empurrará o rim para cima e os dedos o sentirão deslisar para a loja. Esta sensação é muito caracteristica. Este processo exige, entretanto, virtuosidade palpatoria.

Processo de Devoto - é apenas modificação do processo de Glenard: a mão abdominal é colocada logo abaixo da reborda costal, e com o dedo indicador procura-se sentir o rim no fim da inspiração.

\section{Palpação em posição lateral:}

Processo de Israel - Doente em decubito lateral do lado oposto ao que se vae examinar e a perna daquele lado ficará em estensão e a 
outra em flexão sobre a bacia. O medico ficará do lado do rim que vae palpar, como a figura 6 mostra; e colocará a mão direita para o rim esquerdo e a esquerda para o rim direito no angulo costo-lombar como no processo de GLENARD afim de fazer pressão no sentido

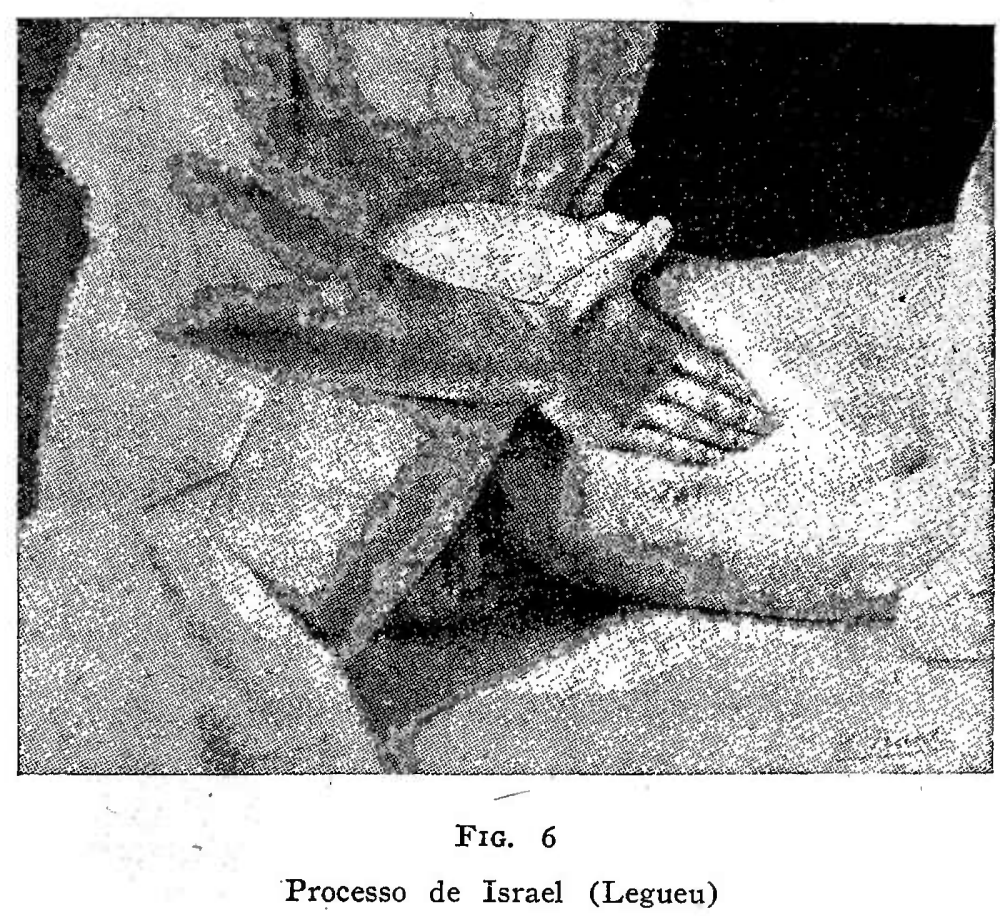

postero-anterior e trazer o rim mais para a superficie. A outra mão permanecerá na parede anterior do abdomen os dedos penetrando por debaixo das falsas costclas na junção das nona e decima eartilagens costaes. Procura-se palpar o rim em sua descida inspiratoria a medida que a mão abdominal vae conseguindo maior relaxamento muscular e estuda-se seus caracteristicos como nos demais processos. A vantagem do metodo é que desloca o rim mais para baixo e para dentro libertando sua face anterior do intestino delgado, figado e baço respectivamente. $E$ ' processo de bons resultados e não exige qualidades palpatorias especiaes. Rins patologicos, volumosos, caem mais pesadamente e a mão abdominal os sente deslisar sob a parede.

Processo de Pasteau - (decubito lateral arqueado) é modificação do processo de Israel mas sem aprescntar vantagens.

Palpação em posição ortostatica: Esta posição é usada com o fim de tornar o rim mais accessivel pela queda que sofre.

Processo de Lepoutre - Doente colocado de pé, diante de uma mesa cuja altura corresponda a linha bitrocanteriana. A seguir, sem flectir membros inferiores, curva o dorso, deixa cair as mãos espalmadas sobre a mesa, onde se apoia. Póde tambem se apoiar sobre o encosto de uma cadeira. Nessa posição a parede abdominal está bastante relaxada. $O$ medico senta-se do lado que vae examinar. Se fôr o direito a mão esquerda abrangerá o dorso e o polegar virá de- 
primir o vasio costo-iliaco. Seu papel ñão é de palpar: essa mão sustenta o doente e dá ponto de apoio a mão direita que palpa; o polegar preenche a fossa lombar e favorece o deslise do rim para a frente. A mão direita vae palpar o espaço sub-costal, o hipocondrio e o flanco. Para palpar o espaço sub-costal esta mão póde ser colocada no sentido vertical e disposta horizontalmente esplorará hipocrondrio e flanco. Poderemos sentir polo inferior e face anterior do rim com seus caracteristicos palpatorios. Em alguns rins ptosados sente-se 0 polo superior (fig. 7 ).

Processo de Goelet - Doente de pé, dorso encostado em uma parede e joelho do lado que se vae palpar apoiado no assento de uma cadeira ou em suporte qualquer mas de forma a ter a perna em flexão sem contração muscular. Medico como no processo de LEPOUTRE, do lado que se vae palpar colocando as mãos como para o

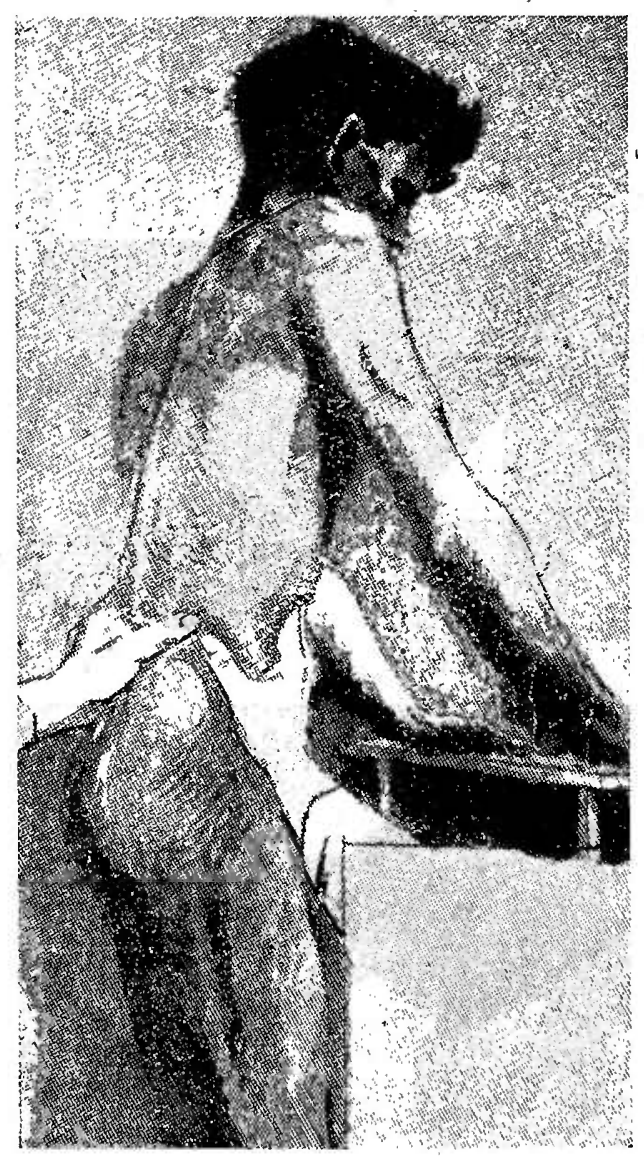

FIG. 7

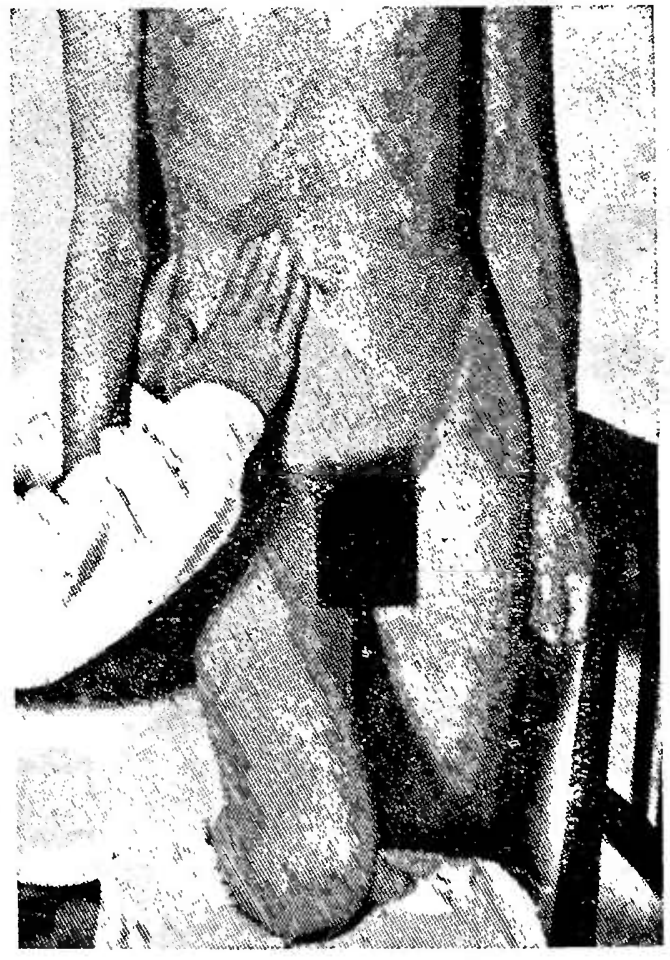

FIG. 8

Processo dé Lepontre (Lepontre) Processo de Goelet (Jairo Ramos e Alipio C. Neto) processo de Guyon (fig. 8). Nos movimentos respiratorios profundos procura-se palpar o rim no final das inspirações. A posição do membro inferior em situação comoda relaxa a musculatura abdominal e dá facil penetração a mão que palpa. 
A figura nove é uma variante do processo de Glenard mas em posição de pé. Nos casos de ptose o gancho que a mão dispõe no flanco prende o rim ptosado que a outra mão vem palpar e caracterisar.

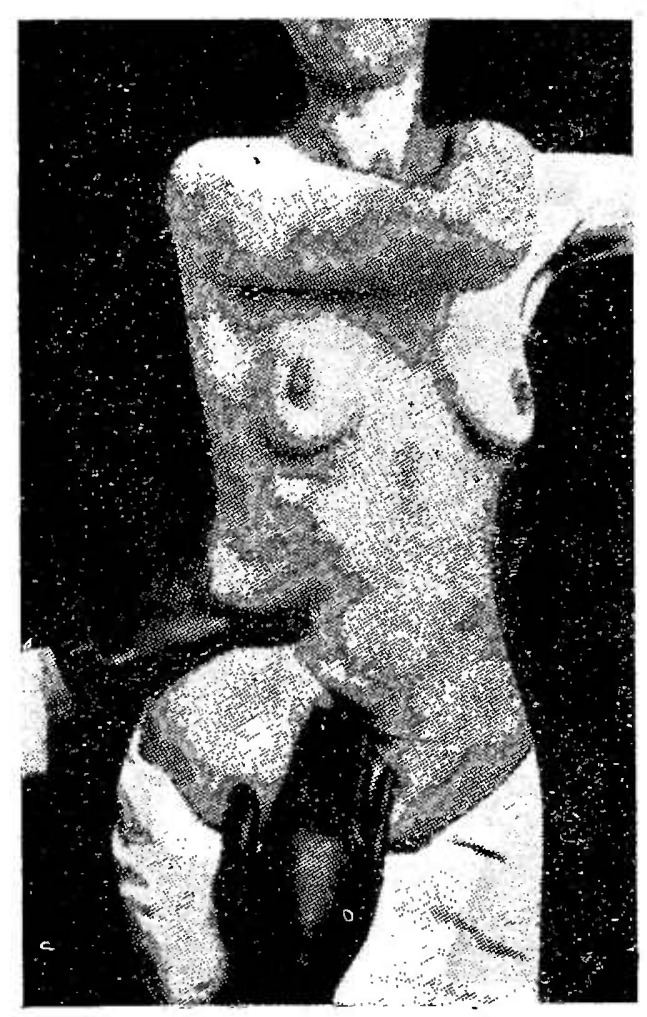

FIG. 9

(Bailey)

Outros processos como o de Pillet utilisam a posição vertical mas são menos praticos. Os que referimos têm aplicação em diferentes casos e o clinico os deve conhecer e tentar antes de declarar os rins como não palpaveis.

Rim ectopico dependendo da posição que ocupe, naturalmente, póde ser reconhecido pela palpação abdominal classica: as duas mãos aplicadas sobre a parede abdominal anterior. O mesmo se fará para palpar o rim em ferradura. 


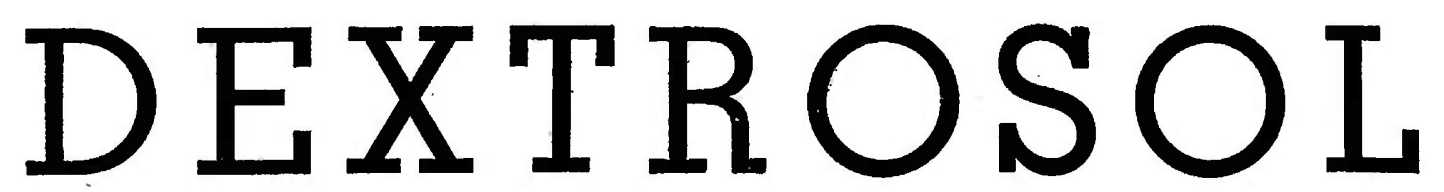

(GLUCOSE-d)

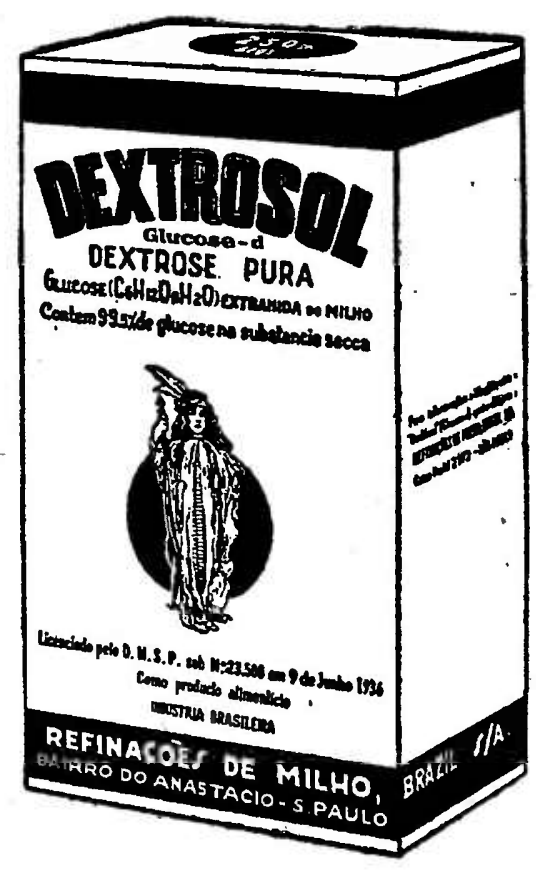

"DRENA AGUA DOS TECIDOS PARA A CIRCULAÇÃO, ELIMINANDO EDEMAS, AUMENTANDO O VOLUME SANGUINEO E PROMOVENDO A DIURESE"

E. MEYER - Usos Terapeuticos das Injeções Endovenosas de Soluções de Glucose) Zentralb. f. klin., Med. 102.343, 1925. Abst. J. A. M. A. 86.521, 1926. 